quả chẩn đoán giữa các chuyên gia GPB [9].

Sự hình thành vi ống và cấp độ hạt nhân là hai thành phần quan trọng khác trong phân loại mô bệnh học của ung thư vú. Tuy nhiên, các phương pháp hoàn toàn tự động cho hai nhiệm vụ này vẫn đang được phát triển. Công việc được công bố hiện tại tập trung vào phân tích cấu trúc mô có thể được sử dụng cho các nhiệm vụ này. Romo-Bucheli và cộng sự đã huấn luyện một mô hình CNN để phát hiện các hạt nhân vi ông và tính toán số liệu thống kê về các hạt nhân để dự đoán các phân loại rủi ro Oncotype DX. Veta và cộng sự đề xuất một loạt các thuật toán phi CNN để phân đoạn và phát hiện hạt nhân. Những phân đoạn này sau đó được sử dung để phát hiện hạt nhân để phân tích hình thái sâu hơn nữa [9].

\section{KẾT LUẦN}

Những tổng quan về những tiến bộ giải phẫu bênh học kỹ thuật số và áp dụng trong ung thư vú trên thế giới đã cho thẩy tiềm năng của việcxây dựng và triển khai ứng dụng AI trong chẩn đoán bệnh lý các bệnh ung thư nói chung và ung thư vú nói riêngtrền ngươơ Việt Nam. ứng dụng AI trong chẩn đoán Ung thư vú dựa trên ảnh giải phẫu bệnh kỹ thuật số hóa sẽ giúp giải quyết những thách thức còn đang tồn tại trong lĩnh vực này và hứa hẹn sẽ mang lại những kết quả đột phá trong tương lai ở Việt Nam.

\section{TÀI LIÊU THAM KHẢO}

1. Prewitt J.M. và Mendelsohn M.L. (1966). The analysis of cell images. Ann N Y Acad Sci, 128(3), 1035-1053.

2. Mukhopadhyay S., Feldman M.D., Abels E. và cô̂ng sự (2018). Whole Slide Imaging Versus Microscopy for Primary Diagnosis in Surgical Pathology: A Multicenter Blinded Randomized Noninferiority Study of 1992 Cases (Pivotal Study). Am J Surg Pathol, 42(1), 39-52.

3. Williams B.J., DaCosta P., Goacher E. và công sư' (2017). A Systematic Analysis of Discordant Diagnoses in Digital Pathology Compared With Light Microscopy. Arch Pathol Lab Med, 141(12), $1712-1718$

4. Ozkan T.A., Eruyar A.T., Cebeci 0.0. và cộng sự (2016). Interobserver variability in Gleason histological grading of prostate cancer. Scand J Urol, 50(6), 420-424.

5. Cruz-Roa A., Gilmore H., Basavanhally A. và công sư (2017). Accurate and reproducible invasive breast cancer detection in whole-slide images: A Deep Learning approach for quantifying tumor extent. Sci Rep, 7, 46450.

6. Han Z., Wei B., Zheng Y. và cộng sự (2017). Breast Cancer Multi-classification from Histopathological Images with Structured Deep Learning Model. Sci Rep, 7(1), 1-10.

7. Ehteshami Bejnordi B., Veta M., Johannes van Diest P. và cộng sự. (2017). Diagnostic Assessment of Deep Learning Algorithms for Detection of Lymph Node Metastases in Women With Breast Cancer. JAMA, 318(22), 2199-2210.

8. Veta M., Heng Y.J., Stathonikos N. và cộng sự. (2019). Predicting breast tumor proliferation from whole-slide images: The TUPAC16 challenge. Med Image Anal, 54, 111-121.

9. Veta M., Kornegoor R., Huisman A. và công sứ. (2012). Prognostic value of automatically extracted nuclear morphometric features in whole slide images of male breast cancer. Mod Pathol Off J U S Can Acad Pathol Inc, 25(12), 1559-1565.

\title{
ĐÁNH GIÁ HIỆU QUẢ DỰ PHÒNG NÔN, BUỒN NÔN BẰNG DEXAMETHASON 8MG VÀ ONDASETRON 4MG TRONG GÂY TÊ TỦY SỐNG BẰNG BUPIVACAIN VÀ MORPHIN TRONG MỔ LẤY THAI
}

TÓM TẮT.

Mục tiêu: Đánh giá hiệu quả dự phòng nôn và buồn nôn bằng dexamethasone $8 \mathrm{mg}$ và ondansetron $4 \mathrm{mg}$ trong gây tê tủy sống bằng bupivacain và morphin sulphat để mổ lấy thai thực hiện tại bệnh

*Bệnh viện phụ sản Hải Phòng

**Dai hoc Y Hà Nôi

***Bênh viện Việt Đức

Chịu trách nhiệm chính: Phạm Thị Anh Tú

Email: phamthianhtu@gmail.com

Ngày nhận bài: 4.01.2021

Ngày phản biên khoa hoc: 26.2.2021

Ngày duyệt bài: 8.3 .2021

\section{Phạm Thị Anh Tú*, Công Quyết Thắng**, Lưu Quang Thùy***}

viện phụ sản Hải phòng trong thời gian từ tháng $10 / 2018$ đến tháng $2 / 2019$. Phương pháp nghiên cứu: Thử nghiệm lâm sàng ngẫu nhiền tiến cứu có so sánh. Nhóm đối chứng (nhóm 1): sử dung thuốc chống nôn bằng dexamethasone $8 \mathrm{mg}$ và nhóm nghiên cứu (nhóm 2): có sử dưng phối hợp thuốc chống nôn dexamethasone $8 \mathrm{mg}$ và ondansetron $4 \mathrm{mg}$. Kết quả nghiên cứu: Tỷ lệ nôn - buồn nôn ở nhóm sử dụng đơn thuần dexamethasone (với 15,6\%) cao hơn so với nhóm sử dụng phối hợp phối hợp dexamethasone và ondansetron (với 6,9\%) với sự khác biệt có ý nghĩa thống kê. Mức độ nôn - buồn nôn ở nhóm sử dụng đơn thuần dexamethason nặng hơn so với nhóm sử dụng phối hợp dexamethasone và ondansetron ở tất cả các các mức độ. Kết luận: Nên sử dụng phối hợp 
dexamethasone và ondansetron để dự phòng nôn, buồn nôn cho bệnh nhân gây tê tủy sống trong mổ lấy thai.

Tư khóa: dexamethasone, ondansetron, gây tê tủy sống

\section{SUMMARY}

EVALUATE THE POSTOPERATIVE NAUSEA AND VOMITING PREVENTION EFFECT OF DEXAMETHASONE 8MG AND ONDASETRON 4MG IN SPINAL ANESTHESIA BY BUPIVACAINE AND MORPHINE IN CESAREAN SECTION

Objective: To evaluate the postoperative nausea and vomiting prevention effect of dexamethasone $8 \mathrm{mg}$ and ondansetron $4 \mathrm{mg}$ in spinal anesthesia with bupivacaine and morphine sulphate for cesarean section performed at Hai Phong Obstetrics Hospital from October 2018 to February 2019. Method: prospective randomized controlled trial interventional study. Control group (group 1): using antiemetics with dexamethasone $8 \mathrm{mg}$, and intervention group (group 2): using a combination of antiemetics with dexamethasone $8 \mathrm{mg}$ and ondansetron $4 \mathrm{mg}$. Results: The vomiting - nausea rate in the group using only dexamethasone (15.6\%) was higher than in the group using the combination of dexamethasone and ondansetron $(6.9 \%)$ with statistically significant difference. The vomiting - nausea level in the group using only dexamethasone was higher than in the group using the combination of dexamethasone and ondansetron. Results: We should apply a combination of dexamethasone and ondansetron to prevent vomiting, nausea for patients with spinal anesthesia during cesarean section.

Key words: dexamethasone, ondansetron, spinal anesthesia.

\section{I. ĐẶT VẤN ĐỀ}

Gây tê tủy sống là một phương pháp vô cảm thường được áp dụng phổ biến cả trên thế giới và Việt Nam để mổ lấy thai. Nhiều nghiên cứu cho thấy viêc tác dung hiêp đồng trong gây tê tủy sống bằng hỗn hợp thuốc tê bupivacain kết hợp với morphin hiện đang được sử dụng phổ biến do hiệu quả kéo dài thời gian giảm đau. Nhưng lại có tác dụng không mong muốn là gây ức chế hô hấp và gây buồn nôn, nôn, ngứa, an thần sâu, bí đái. theo khuyến cáo điều trị của chương trình ERAS cần phải dùng thuốc dự phòng nôn và buồn nôn sau mổ là điều trị bắt buộc cho bệnh nhân mổ [1]. Từ khi khám phá được vùng nhận cảm hóa học CTZ ở sàn não thất IV, các chất trung gian hóa học đồng vận dẫn truyền cảm giác nôn, tại vùng này tới trung tâm nôn ở hành não đã cắt nghĩa được phần nào cơ chế tác dụng phòng nôn của dexamethasone, ondansetron [2]. Tuy nhiên các nghiên cứu bằng nhiều phương thức ở nhiều nơi khác nhau vẫn chưa khẳng định biện pháp dự phòng nôn và buồn nôn nào là hiệu quả nhất. Hiện nay, trên thế giới cũng như ở Việt Nam có nhiều thuốc chống nôn mới đã được nghiên cứu và sử dụng riêng lẻ hoặc phối hợp. Cũng đã có một số nghiên cứu đề phòng nôn và buồn nôn khi phối hợp dexamethasone và ondansetron trong mổ nội soi ổ bụng, tai mũi họng, mổ chi dưới [3],[4]. Trong mổ lấy thai có nguy cơ nôn và buồn nôn sau mổ cao hơn hẳn một số trường hợp khác thì tại thời điểm này ở Việt Nam chúng tổi chưa tìm thấy báo cáo nào về vân đề này. Chính vì vậy chúng tôi tiến hành nghiên cứu đề tài: "Đánh giá hiệu quả dự phòng nôn và buồn nôn bằng dexamethasone $8 \mathrm{mg}$ và ondansetron $4 \mathrm{mg}$ trong gây tê tủy sống bằng bupivacain và morphin sulphat để mổ lấy thai"

\section{II. ĐỐl TƯợNG VÀ PHƯƠNG PHÁP NGHIÊN CỨU \\ 2.1 Đối tượng nghiên cứu}

- Tiêu chuấn lứa chon: Sản phụ có tinh thần tỉnh táo. Tình trạng sức khỏe ASA I, II. Sản phụ được chỉ định mổ lấy thai chủ động. Có chỉ định với GTTS. Không sử dụng thuốc chống nôn hoặc các thuốc có thể gây tăng tỷ lệ nôn, buồn nôn trước mổ. Đồng ý tham gia nghiển cứu

- Tiêu chuẩn loại trừ: Sản phụ có khó khăn trong giao tiếp, mắc bệnh động kinh hay tâm thần, tiền sử hay hiện tại nghiện ma túy. Có chống chỉ định gây tê tủy sống hoăc không thực hiện được kỹ thuật gây tê. Có triệu chứng nổn và buồn nôn trước mổ. Các trường hợp có tai biến, biến chứng của mổ như chảy máu nhiều, tụt huyết áp nặng, suy hô hấp... Sản phụ dị ứng với các thành phần của thuốc bupivacain, morphin sulphat, ondansetron và dexamethasone. Sản phụ không đồng ý tham gia nghiên cứu.

2.2 Địa điểm và thời gian nghiên cứu. Đề tài thực hiện tại khoa Gây mê hồi sức Bệnh viện Phụ Sản Hải Phòng. Tiến hành từ tháng 10/2018 đên tháng 2/2019.

2.3 Phương pháp nghiên cứu. Thử nghiệm lâm sàng ngẫu nhiên tiến cứu có so sánh. Chọn ngẫu nhiên theo phương pháp bốc thăm, chia làm hai nhóm bằng nhau với nhóm đối chứng (nhóm1: sử dụng thuốc chống nôn bằng dexamethasone $8 \mathrm{mg}$ ) và nhóm nghiên cứu (nhóm 2: có sử dụng phối hợp thuốc chống nôn dexamethasone $8 \mathrm{mg}$ và ondansetron $4 \mathrm{mg}$ ). Mỗi bệnh nhân sẽ tương ứng với một lần bắt thăm, bắt được thăm nào thì xếp vào nhóm đó và thực hiện đúng theo phương pháp đó. Mỗi nhóm được tiến hành nghiên cứu và thu thập số liệu như nhau.

Tiêu chí đánh giá: Ngoài các tiêu chí chung về 
tuổi, giới, cân nặng, loại hình phẫu thuật. Chúng tôi đánh giá mức độ vồ cảm của phẫu thuật dựa vào thang điểm Abouleizh và đánh giá mức độ nôn và buồn nôn dựa vào thang điểm Klockgether-radle [5].

\begin{tabular}{|l|l|}
\hline Mức độ 0 & Không nôn và không buồn nôn \\
\hline
\end{tabular}

- Các thời điểm đánh giá:

\begin{tabular}{|c|c|c|c|}
\hline Ký hiệu & Thời điếm & Ký hiệu & Thời điếm \\
\hline $\mathbf{H}_{\mathbf{0}}$ & Trước khi gây tê & $\mathbf{H}_{\mathbf{3 0}}$ & Sau khi gây tê 30 phút \\
\hline $\mathbf{H}_{\mathbf{1}}$ & Ngay sau khi gây tê & $\mathbf{H}_{\mathbf{K T}}$ & Kết thúc cuộc mố \\
\hline $\mathbf{H}_{\mathbf{5}}$ & Sau khi gây tê 5 phút & $\mathbf{H}_{\mathbf{s 2}}$ & Sau mố 2 giờ \\
\hline $\mathbf{H}_{10}$ & Sau khi gây tê 10 phút & $\mathbf{H}_{\mathbf{s 6}}$ & Sau mố 6 giờ \\
\hline $\mathbf{H}_{15}$ & Sau khi gây tê 15 phút & $\mathbf{H}_{\mathbf{s 2 4}}$ & Sau mố 24 giờ \\
\hline
\end{tabular}

2.4 Xử lý số liệu: Số liệu thu thập được mã hóa, nhập vào máy tính và xử lý theo chương trình SPSS 12.0 và phần mềm Microsoft Excel 2007.

III. KẾT QUẢ NGHIÊN CỨU

3.1 Đặc điểm chung của 2 nhóm nghiên cứu

Bảng 3.1. Phân bố về tuối, chiều cao, cân năng và chỉ số BMI

\begin{tabular}{|c|c|c|c|c|c|}
\hline Chỉ số & Nhóm NC & T’ân số & Trung bình & SD & $\mathbf{p}$ \\
\hline \multirow{2}{*}{$\begin{array}{l}\text { Tuối trung bình } \\
\text { (năm) }\end{array}$} & Nhóm 1 & 32 & 31,6 & 4,5 & \multirow{2}{*}{$>0,05$} \\
\hline & Nhóm 2 & 58 & 29,8 & 3,8 & \\
\hline \multirow{2}{*}{$\begin{array}{l}\text { Chiều cao } \\
\text { (cm) }\end{array}$} & Nhóm 1 & 32 & 157,0 & 5,0 & \multirow{2}{*}{$>0,05$} \\
\hline & Nhóm 2 & 58 & 156,1 & 4,4 & \\
\hline \multirow{2}{*}{$\begin{array}{l}\text { Cân nă̆ng } \\
\text { (kg) }\end{array}$} & Nhóm 1 & 32 & 64,3 & 6,5 & \multirow{2}{*}{$>0,05$} \\
\hline & Nhóm 2 & 58 & 65,2 & 7,6 & \\
\hline \multirow{2}{*}{$\begin{array}{c}\text { BMI } \\
\left(\mathrm{kg} / \mathrm{m}^{2}\right)\end{array}$} & Nhóm 1 & 32 & 26,1 & 2,5 & \multirow{2}{*}{$>0,05$} \\
\hline & Nhóm 2 & 58 & 26,8 & 3,2 & \\
\hline
\end{tabular}

Nhận xét: Không có sự khác biệt có ý nghĩa giữa 2 nhóm về các đặc điểm nhân trắc học

3.2 Mức độ vô cảm

Bảng 3.2. Thời gian vô cảm

\begin{tabular}{|c|c|c|c|c|c|}
\hline Thời gian Chỉ số & Nhóm NC & Tần số & Trung bình & SD & $\mathbf{p}$ \\
\hline \multirow{2}{*}{$\begin{array}{l}\text { Thời gian onset } \\
\text { (phút) }\end{array}$} & Nhóm 1 & 32 & 4,66 & 0,75 & \multirow{2}{*}{$>0,05$} \\
\hline & Nhóm 2 & 58 & 4,33 & 1,14 & \\
\hline \multirow{2}{*}{$\begin{array}{l}\text { Thời gian mố } \\
\text { (phút) }\end{array}$} & Nhóm 1 & 32 & 36,44 & 9,23 & \multirow{2}{*}{$>0,05$} \\
\hline & Nhóm 2 & 58 & 37,40 & 7,84 & \\
\hline \multirow{2}{*}{$\begin{array}{l}\text { Thời gian vô cảm } \\
\text { (phút) }\end{array}$} & Nhóm 1 & 32 & 89,52 & 17,21 & \multirow{2}{*}{$>0,05$} \\
\hline & Nhóm 2 & 58 & 88,65 & 18,72 & \\
\hline
\end{tabular}

Nhận xét: Không có sự khác biệt giữa 2 nhóm về mức độ vô cảm với $\mathrm{p}>0,05$

3.3 Đánh giá hiệu quả dự phò̀ng nôn, buồn nôn

Bảng 3.3. Tỷ lệ sán phụ nôn, buồn nôn trong mổ và sau mổ

\begin{tabular}{|c|c|c|c|c|c|c|c|}
\hline \multirow{2}{*}{ Đặc điểm } & \multicolumn{2}{|c|}{ Nhóm $1(n=32)$} & \multicolumn{2}{|c|}{ Nhóm $2(n=58)$} & \multicolumn{2}{|c|}{ Tống số $(n=90)$} & \multirow[b]{2}{*}{$\mathbf{p}$} \\
\hline & Tân số & Tỷ lệ & Tân số & Tỷ lề & Tân số & Tỷ lề & \\
\hline Không nôn & 27 & $84,4 \%$ & 54 & $93,1 \%$ & 81 & $90 \%$ & \\
\hline Nôn-buồn nôn & 5 & $15,6 \%$ & 4 & $6,9 \%$ & 9 & $10 \%$ & $<0,05$ \\
\hline
\end{tabular}

Nhận xét: Tỉ lệ nôn, buồn nôn ở nhóm 1 (sử dụng đơn độc dexamethasone) nhiều hơn nhóm 2 (kết hợp dexamethasone và ondansetron) có ý nghĩa thống kê với $p<0,05$.

Bảng 3.4. Phân bố mức độ nôn, buồn nôn theo Klockgether-Radke tại các thời điểm

\begin{tabular}{|c|c|c|c|c|c|c|c|c|c|c|}
\hline \multirow{2}{*}{ Thời điểm Mức độ } & \multicolumn{2}{|c|}{ Độ 0} & \multicolumn{2}{|c|}{ Độ 1} & \multicolumn{2}{|c|}{ Độ 2} & \multicolumn{2}{|c|}{ Độ 3} & \multicolumn{2}{|c|}{ Độ 4} \\
\hline & $\mathbf{n}$ & $\%$ & $\mathbf{n}$ & $\%$ & $\mathbf{n}$ & $\%$ & $\mathbf{n}$ & $\%$ & $\mathbf{n}$ & $\%$ \\
\hline Thời điếm H0 & 90 & 100 & & & & & & & & \\
\hline Thời điếm H1 & 88 & 97,8 & 2 & 2,2 & & & & & & \\
\hline Thời điểm H5 & 83 & 92,2 & 5 & 5,6 & 2 & 2,2 & & & & \\
\hline
\end{tabular}


TẠP CHÍ Y HỌC VIẸT NAM TẬP 500 - THÁNG 3 - SÓ 1 - 2021

\begin{tabular}{|c|c|c|c|c|c|c|c|c|c|c|}
\hline Thời điếm H10 & 83 & 92,2 & 3 & 3,35 & 3 & 3,35 & 1 & 1,1 & & \\
\hline Thời điếm H15 & 82 & 91,1 & 2 & 2,2 & 3 & 3,35 & 3 & 3,35 & & \\
\hline Thời điếm H30 & 81 & 90 & 1 & 1,1 & 3 & 3,35 & 2 & 2,2 & 3 & 3,35 \\
\hline Thời điếm KT & 81 & 90 & 2 & 2,2 & 1 & 1,1 & 2 & 2,2 & 4 & 4,5 \\
\hline Thời điếm S2 & 81 & 90 & 4 & 4,5 & 3 & 3,35 & 1 & 1,1 & 1 & 1,1 \\
\hline Thời điếm S6 & 84 & 93,3 & 5 & 5,6 & 1 & 1,1 & & & & \\
\hline Thời điếm S24 & 89 & 99,9 & 1 & 1,1 & & & & & & \\
\hline
\end{tabular}

Nhân xét: Mức độ 4 chỉ găp ở 4 bênh nhân tai thời điếm 30 phút sau tê, 3 bênh nhân tai lúc kết thúc mổ và chỉ có 1 bệnh nhân ở 2 giờ sau mổ. Sau 24h sau mổ thì chỉ có 1 bệnh nhân là có mức độ 1 .

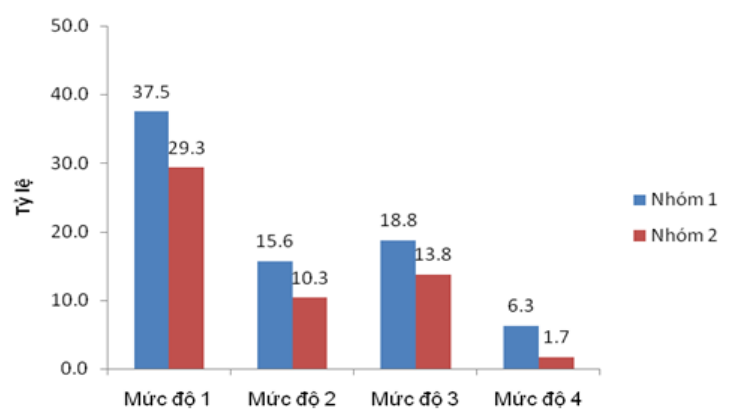

Biểu đồ 3.1. Phân bố mức độ nôn, buồn nôn ở các nhóm

Nhận xét: Ta đều nhận thấy là mức độ nôn, buồn nôn ở cả 4 mức độ thì nhóm 2 đều có tỉ lệ thấp hơn so với nhóm 1.

\section{BÀN LUẬN}

Qua kết quả nghiên cứu cho thây trong tổng số cả 2 nhóm nghiên cứu có tới $90 \%$ sản phụ không có các dấu hiện buồn nôn hay nôn và chỉ có $10 \%$ các sản phụ có nôn và/hoặc buồn nôn trong mổ và 24 giờ sau mổ. Đặc biệt, tỷ lệ có nôn và/hoặc buồn nôn ở nhóm 1 là nhóm chỉ dự phòng nôn, buồn nôn bằng dexamethasone có 5 sản phụ tương ứng với $15,6 \%$ và ở nhóm 2 là nhóm dự phòng nôn, buồn nôn bằng dexamethasone phối hợp với ondansetron chỉ có 4 sản phụ tương ứng với $6,9 \%$. Khác biệt có ý nghĩa thống kê $(p<0,05)$. Theo nghiên cứu của Đồ Thanh Hòa cho thấy tỷ lệ nôn, buồn nôn sau mổ ở nhóm được dự phòng bằng dexamethasone kết hợp với ondansetron thấp hơn hẳn khi chỉ dự phòng bằng dexamethasone đơn thuần trong gây tê tủy sống để phẫu thuật chi dưới [6]. Một nghiên cứu trước đây cho rằng cơ chế hoạt động chống nôn, buồn nôn của dexamethasone có thể đối kháng với chất trung gian prostaglandin hoặc gây phóng thích endorphins, những kết quả này sẽ làm nâng cao điểm nhạy cảm, cân bằng cảm giác và gây thèm ăn dẫn đến làm giảm cảm giác nôn, buồn nôn [7]. Đồng thời với đó và/hoặc có thể do cơ chế đối kháng với dopamin receptor tại vùng nhận cảm hóa học (CTZ) ở sàn não thất IV làm cho nồng độ dopaminnergic bị giảm đáng kể tác dụng tại vùng này. [7]. Ngoài ra, nhiều tác giả cũ̃ng đã ghi nhận nếu kết hợp dự phòng bằng dexamethasone cùng với ondansetron là môt chất ức chế thụ thể 5 -HT3 sẽ cho kết quả dự phòng hiệu quả cao hơn. Theo một nghiên cứu của Tramer và cộng sự cho rằng, liều lượng tối thiểu $8 \mathrm{mg}$ ondansetron là cần thiết để ngăn chặn các thụ thể 5-HT3 ở một bệnh nhân nôn mửa[8]. Trong kết quả nghiên cứu của chúng tôi đã sử dụng dự phòng nôn, buồn nôn sau mổ bằng dexamethasone đơn thuần hay dexamethasone phối hợp cùng với ondansetron nên tỷ lệ các sản phụ không nôn-buồn nôn (mức độ 0 ) chiếm tỷ lệ cao. Tại một số thời điểm cự thể của cuộc mổ và quá trình hồi phục sau mổ thì tỷ lệ này có thay đổi nhưng không đáng kể, như các thời điểm trong mổ như H30 không nôn-buồn nôn (mức độ 0) chiểm tỷ lệ thấp giống với các thời điêm HKT và thời điểm S2 với $90 \%$ sau đó tăng dần ở các thời điểm S6 với 93,3\% và cao nhất ở thời điểm H24 với 99,9\%. Tỷ lệ nôn ở mức độ 1 gặp rải rác từ thời gian sau khi tiến hành gây tê đến sau mổ 24 giờ, trong đó nhóm chỉ dự phòng nôn, buồn nôn bằng dexamethasone có tỷ lệ cao hơn nhóm được dự phòng bằng dexamethasone phối hợp cùng với ondansetron. Nôn ở mức độ 1 chủ yểu tập chung vào thời điểm $\mathrm{H} 5$ với $5,6 \%$, thời điểm $\mathrm{H} 10$ với $3,35 \%$, thời điểm S2 với $4,5 \%$ và thời điểm S6 với 5,6\%. Tỷ lệ nôn ở mức độ 2 thường gặp trong thời gian thời điểm $\mathrm{H} 5$ với 2,2\%, thời điểm $\mathrm{H} 10, \mathrm{H} 15$ và $\mathrm{H} 30$ với $3,35 \%$, thời điểm $\mathrm{S} 2$ với $3,35 \%$ và thời điểm $\mathrm{S} 6$ với $1,1 \%$. Tỷ lệ nôn ở mức độ 3 chủ yếu gặp từ thời điểm H15 với $3,35 \%$; thời điểm $\mathrm{H} 30$ và thời điểm $\mathrm{HKT}$ với $2,2 \%$ và cho đến khoảng thời gian S2 với $1,1 \%$. Nôn ở mức độ 4 chiếm tỷ lệ cao tại thời điểm $\mathrm{H} 30$ và thời điểm $\mathrm{HKT}$ lần lượt là $3,35 \%$ và 4,5\%. Sau mổ tỷ lệ nôn mức độ 4 chỉ chiểm $1,1 \%$ ở thời điểm S2. Nhưng khi đánh giá riêng theo từng nhóm thì tỷ lệ gặp sản phụ nôn, buồn nôn các mức độ ở nhóm dự phòng dexamethasone đơn thuần đều cao hơn nhóm được dự phòng bằng dexamethasone phối hợp 
cùng với ondansetron. Đồng thời, tỷ lệ nôn, buồn nôn là tương đối thấp và chủ yếu chỉ gặp nôn, buồn nôn ở mức độ 1 ; các mức độ khác, đặc biệt là mức độ 4 giảm thấp. Khi so sánh kết quả nghiên cứu của chúng tôi với các tác giả khác như Đố Thanh Hòa cho thây ở mức độ 1 , tỉ lệ nôn, buồn nôn ở nhóm dự phòng dexamethasone đơn thuân và nhóm được dự phòng bằng dexamethasone phối hợp cùng với ondansetron là không khác nhau, nhưng ở mức độ cao hơn là mức 2,3,4 ở nhóm dự phòng dexamethasone đơn thuần là cao hơn nhóm phối hợp [6]. Các nghiên cứu khác cũng cho kết quả tương tự như nghiên cứu của chúng tôi về sự hiệu quả của dự phòng nôn bằng dexamethasone và ondansetron trong mổ [9].

\section{KẾT LUÂ̂N}

- Tỷ lệ nôn - buồn nôn ở nhóm sử dụng đơn thuần dexamethasone (với 15,6\%) cao hơn so với nhóm sử dụng phối hợp phối hợp dexamethasone và ondansetron (với 6,9\%) với sự khác biệt có ý nghĩa thống kê.

- Mức đô nôn, buồn nôn ở mức đô 3 và 4 chiếm tî lệ nhỏ và chỉ ở một vài thời điểm nhất định trong cuộc mổ

- Mức độ nôn - buồn nôn ở nhóm sử dụng đơn thuần dexamethason nặng hơn so với nhóm sử dụng phối hợp dexamethasone và ondansetron ở tất cả các các mức độ.

\section{TÀI LIÊU THAM KHẢO}

1. Công Quyết Thắng (2017), ERAS: Enhanced Recovery After Surgery- Tăng cường hồi phuc sau phẫu thuật và vai trò của người làm Gây mê Hồi sức. Hội Gây mê Hồi sức Việt Nam (VSA).

2. Bộ Y Tế (2002), "Dexamethasone". Dược Thư Quốc Gia Viêt Nam, 356-357.

3. Nguyển Đình Long (2011), So sánh tác dụng dự phòng và điều trị nôn và buôn nôn của ondansetron với dexamethasone sau mổ nội soi phụ khoa. Luận văn Thạc sĩ. Đại học y Hà Nội.

4. Đố Thanh Hòa (2012), Nghiên cứu tác dụng dự phòng buồn nôn và nôn của dexamethasone đơn thuân hoặc kễ̂t hợp với ondansetron sau gây tê tủy sống trong phấu thuât chi dưới. Y học thực hành, 841.

5. Klockgether-Radke, A., et al. (1996), Nausea and vomiting after laparoscopic surgery: a comparison of propofol and thiopentone/halothane anaesthesia. European journal of anaesthesiology, 13(1): 3-9.

6. Đô̂ Thanh Hòa, Nguyễn Văn Phương (2012), nghiên cứu tác dụng dư phòng nôn và buồn nôn cúa Dexamethasone đợn thuân hoặc kêtt hợp với ondansetron sau gây tê tủy sống trong phâuu thuật chi dưới. Y học thực hành, 841(số 9/2012): 58-62.

7. Tugsan E $B, \dot{H}$ andan $B$ et al (2008), $A$ comparative study of the antiemetic efficacy of dexamethasone, ondansetron, and metoclopramide in patients undergoing gynecological surgery. Anaesthsia, 2: 226-234.

8. Tramer MR, et al. (1999), Cost-effectiveness of ondansetron for postoperative nausea and vomiting. Anaesthsia, 54: 226-234.

9. Nguyến Minh Hải (2011), So sánh tác dụng dư phòng buồn nôn và nôn của ondansetron và metoclopramid sau phấu thuât nội soi ổ bụng, Luận văn thạc sỹ y học, Học viện Quân y 2011.

\section{ĐĂC ĐIỂM LÂM SÀNG CỦA NGƯỜI KHIẾM THI TUỔI TRƯỞNG THÀNH}

\section{TÓM TẮT}

Mục tiêu: Mô tả đặc điểm lâm sàng của người khiếm thị ở tuổi trưởng thành. Phương pháp nghiên cứu: nghiên cứu mồ tả được thực hiện trên 167 trường hợp đáp ứng đây đủ các tiêu chuẩn theo yêu cầu của nghiên cứu. Kết quả: Tuổi trung bình là $31,46 \pm 16,47$; bênh nhân cao tuổi nhất là 78 tuổi và trẻ nhất là 18 tuổi. Bệnh nhân chưa lập gia đình và sống cùng bố mẹ chiếm nhiều nhất $56,3 \%$. Nguyên nhân gây khiếm thị theo bệnh học: nhóm nguyên nhân thường gặp nhất là các bẹnh lý thể thủy tinh

\section{${ }^{1}$ Bệnh viện Mắt trung ương}

Chịu trách nhiệm chính: Nguyễn Thị Thu Hiền

Email: Thuhienvnio@gmail.com

Ngày nhận bài: 24.12.2020

Ngày phản biện khoa học: 15.2.2021

Ngày duyệt bài: 24.2.2021

\section{Nguyễn Thị Thu Hiền ${ }^{1}$}

34,1\%; nhóm nguyên nhân thường găp thứ hai là các bệnh lý võng mạc hoàng điểm $23,3 \%$; nhóm nguyên nhân thường gặp thứ ba là các tổn hại của thị thần kinh $14,4 \%$. Thị lực nhìn xa không kính trung bình là 20/333 \pm 20/500; 41,3\% trường hơp thi lực nhìn xa cải thiện với kính chỉnh tật khúc xạ tối ưu. 73,7\% trường hợ khả năng nhay cảm tương phản tốt dưới $10 \%$. Tất cả các trường hợp bệnh glôcôm và bệnh thoái hóa sắc tố võng mạc đều tổn hại thị trướng ngoại vi mức độ nặng. Thị lực gân tốt nhất trung bình là $20 / 285 \pm 20 / 400$. Thi lức xa và thi lực gần có mối liên quan tuyến tính mức độ trung bình với $r=0,45$ ( $p$ $=0,001)$. Kết luân: Tuổi của bệnh nhân: hầu hết ở lứa tuổi lao động, chủ yếu sông cùng với gia đình hoăcc người thân. Nguyên nhân gây khiếm thị chủ yếu là bệnh lý của thể thuỷ tinh. Tình trạng thị lực xa rất kém, cải thiện với kính chỉnh tật khúc xạ. Khả năng nhạy cảm tương phản tốt chiếm 73,7\% trường hợp. Thị trường ngoại vi bị tổn hại nặng và khó đánh giá. 